\title{
8
}
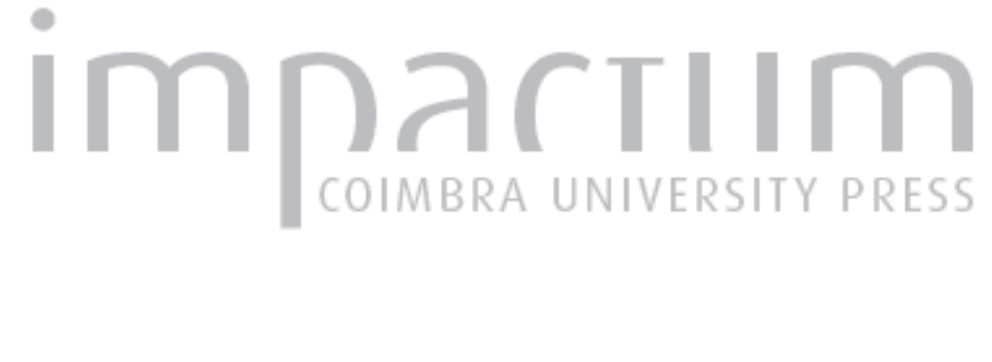

\section{Povoamento rural romano ao longo da Ribeira da Meimoa - Fundão: 1a campanha de prospecção intensiva}

\author{
Autor(es): $\quad$ Carvalho, Pedro C.; Ribeiro, Carla Alegria; Silva, Ricardo Costeira da; \\ Almeida, Sara Oliveira
}

Publicado por: Faculdade de Letras da Universidade de Coimbra

URL

persistente:

URI:http://hdl.handle.net/10316.2/37667

DOI:

DOI:http://dx.doi.org/10.14195/1647-8657_41_5

Accessed : $\quad$ 26-Apr-2023 00:20:54

A navegação consulta e descarregamento dos títulos inseridos nas Bibliotecas Digitais UC Digitalis, UC Pombalina e UC Impactum, pressupõem a aceitação plena e sem reservas dos Termos e Condições de Uso destas Bibliotecas Digitais, disponíveis em https://digitalis.uc.pt/pt-pt/termos.

Conforme exposto nos referidos Termos e Condições de Uso, o descarregamento de títulos de acesso restrito requer uma licença válida de autorização devendo o utilizador aceder ao(s) documento(s) a partir de um endereço de IP da instituição detentora da supramencionada licença.

Ao utilizador é apenas permitido o descarregamento para uso pessoal, pelo que o emprego do(s) título(s) descarregado(s) para outro fim, designadamente comercial, carece de autorização do respetivo autor ou editor da obra.

Na medida em que todas as obras da UC Digitalis se encontram protegidas pelo Código do Direito de Autor e Direitos Conexos e demais legislação aplicável, toda a cópia, parcial ou total, deste documento, nos casos em que é legalmente admitida, deverá conter ou fazer-se acompanhar por este aviso.

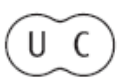




\section{CONIMBRIGA}

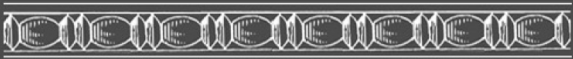

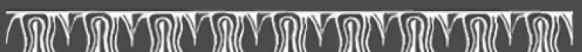
2

INSTITUTO DE ARQUEOLOGIA

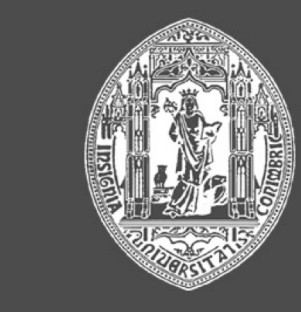

VOLUME XLI - 2002

F A C U L D A E D E LETRAS UNIVERSIDADE DE COIMBRA 
Pedro C. Carvalho

Instituto de Arqueologia. Faculdade de Letras da Universidade de Coimbra.

Carla Alegria Ribeiro

RicARdo COSTEIRA DA SILVA

SARa Oliveira Almeida

Licenciados em História - variante de Arqueologia pela FLUC.

POVOAMENTO RURAL ROMANO AO LONGO DA RIBEIRA DA MEIMOA - FUNDÃO (1ª CAMPANHA DE PROSPECÇÃO INTENSIVA) "Conimbriga" XLI (2002) p. 127-152

REsumo: Apresenta-se o resultado de prospecções intensivas efectuadas ao longo do curso da Ribeira da Meimoa (Fundão, Castelo Branco) e analisa-se a forma como o povoamento rural romano se encontra distribuído pela paisagem e se relaciona com os recursos naturais e o território construído.

RÉSUMÉ: Cet article présente les résultats de prospections intensives effectuées dans la vallée de la rivière de Meimoa (Fundão, Castelo Branco). La forme d'organisation du peuplement rural romain dans le quadre du paysage est également analisée, ainsi que sa relation avec les ressources naturelles et le territoire construit. 
(Página deixada propositadamente em branco) 


\section{POVOAMENTO RURAL ROMANO AO LONGO DA RIBEIRA DA MEIMOA - FUNDÃO (1ª CAMPANHA DE PROSPECÇÃO INTENSIVA)}

\section{Nota introdutória}

Nas últimas duas décadas tem-se assistido a um interesse crescente pela realização de estudos de arqueologia espacial ou, numa perspectiva mais recente, de arqueologia da paisagem.

Mais do que procurar descrever e classificar individualmente e isoladamente cada estação arqueológica, procura-se hoje analisar o conjunto de estações de uma região, mas de modo a que este tipo de análise não termine com os processos de cartografia e inventário. Com efeito, o objectivo geral deste tipo de abordagem consiste na determinação e compreensão do padrão de povoamento rural numa dada região, procurando-se para isso relacionar entre si as estações cronologicamente contemporâneas (definindo funcionalidades e hierarquias), relacionar as estações com o meio físico e ambiental (determinando o grau de influência das variáveis geo-ambientais na localização e estruturação do povoamento, sendo para isso fundamental a identificação de todos os recursos bioenergéticos envolventes potencialmente exploráveis) e relacionar as estações com os restantes elementos construídos que configuram e articulam a paisagem e o território (caminhos, parcelamento, sistemas de regadio).

Esta análise morfológica da matriz de ocupação da paisagem poderá permitir, por sua vez, delinear os contornos da estrutura sócio-económica que a materializou e utilizou, uma vez que as paisagens antigas constituirão uma resultante quer da intervenção do homem no espaço físico ou no meio natural que o circundava, quer da complexa e dinâmica rede de relações sociais, económicas, políticas e ideológicas ou simbólicas que se foram estabelecendo ${ }^{1}$.

1 É já extensa a bibliografia que aborda as questões teóricas e metodológicas 
Foi precisamente por ser este o nível ou escala de análise que pretendemos adoptar como fio condutor do projecto de investigação sobre o Povoamento Romano na Região da Cova da Beira ${ }^{2}$, da responsabilidade de um dos autores deste texto, que iniciámos em 2001 a implementação no terreno de um programa de prospecções intensivas de superfície. A adopção desta estratégia de intervenção resultou do facto de considerarmos que apenas esta metodologia de trabalho de campo seria capaz de reunir um conjunto de dados que pudessem constituir uma amostragem suficientemente válida e representativa da variedade, distribuição e evolução do povoamento antigo ${ }^{3}$.

Certamente por insuficiência de meios e/ou pelas particulares características geo-ambientais de determinadas regiões, alguns dos estudos sobre o povoamento romano entretanto realizados em território nacional têm privilegiado as prospecções de tipo extensivo, nas quais se seleccionam para visitar, com base em critérios pré-definidos (geomorfologia, pedologia, toponímia, informações orais, referências bibliográficas), algumas áreas alegadamente com um maior potencial arqueológico. Todavia, a prática exclusiva desta metodologia é, em nosso entender, manifestamente insuficiente para validar esse tipo de estudo, dado o carácter extremamente lacunar que o conjunto de dados recolhidos assume. Esta estratégia de trabalho de campo poderá inclusivamente orientar-se no sentido dos resultados confirmarem o modelo teórico inicialmente gizado, conduzindo preferencialmente a sítios que se procuram e/ou cujas características os fazem mais facilmente distinguíveis.

Sendo assim, o conjunto de dados que permitam definir modelos de ocupação e organização do povoamento deverão antes resultar da execução de um plano de prospecções sistemáticas efectuadas por uma equipa alargada de elementos que percorram intensivamente o terreno

relacionadas com a arqueologia da paisagem; cf., a título de exemplo, a colectânea de textos dirigida por Gérard Chouquer: Les Formes du Paysage, vols. 1 - 3, Errance, Paris, 1996-1998; ou as reflexões de Almudena Orejas: "Arqueologia del paisaje: de la reflexión a la planificación”, Archivo Español de Arqueología, 68 (n. $\left.{ }^{\circ} 171-172\right)$, CSIC, 1995, p. 215-224 e "El estudio del paisaje: visiones desde la arqueologia", Arqueologia Espacial, 19-20, Teruel, 1998, p. 9-19.

2 Inscrito no Plano Nacional de Trabalhos Arqueológicos: 2000-2003 (IPA).

3 A este propósito cf., a título de exemplo: Alain Ferdière, La prospection archéologique, Editions Errance, Paris, 1998. 
espaçados a intervalos regulares. Parece-nos igualmente fundamental, na perspectiva de procurar definir parâmetros básicos que permitam avaliar e comparar os resultados de diversas prospecções, que se caminhe no sentido da normalização dos processos de recolha e registo dos dados e da uniformização dos critérios de classificação tipológica dos sítios. Desejavelmente, e de modo a validar ou precisar essas classificações tipológicas (e cronológicas) ou, pelo menos, de forma a minimizar o grau de subjectividade das mesmas, algumas das estações assim identificadas deveriam ser ainda objecto quer de sondagens de diagnóstico ou de controlo, quer de trabalhos de prospecção intensiva por quadriculagem levadas a cabo na área das próprias estações e na sua envolvente imediata.

Reservamos para outra oportunidade uma reflexão e explanação mais circunstanciada sobre algumas questões de ordem teórica e metodológica que os trabalhos de prospecção e os estudos sobre o povoamento rural romano suscitam. Neste artigo, procuramos apenas registar os dados da prospecção efectuada e interpretá-los de uma forma genérica.

\section{Alguns aspectos metodológicos}

Com base nos resultados dos trabalhos de prospecção extensiva efectuados durante o ano 2000, no âmbito do projecto de investigação acima referido, e tomando como ponto de partida os trabalhos de prospecção anteriormente efectuados por José Cristóvão nesta região ${ }^{4}$, foi seleccionada uma área com cerca de $43,5 \mathrm{~km}^{2}$, envolvendo parte do território das freguesias de Capinha, Salgueiro e Escarigo (Fundão), e abarcando distintos contextos geográficos e ambientais posicionados ao longo dos cursos médio e inferior da Ribeira da Meimoa, cujas características de terreno, designadamente a sua cobertura vegetal e consequente visibilidade do solo, davam garantias de possibilitar a planificação e execução de um programa de prospecções intensivas de

4 CRISTÓVÃo, J. L., O povoamento romano da bacia do curso médio da Ribeira da Meimoa, Instituto de Arqueologia da Faculdade de Letras da Universidade de Coimbra, Coimbra, 1992 (seminário de Arqueologia: trabalho académico policopiado). 
cobertura total ${ }^{5}$. Esta área foi seleccionada também pelo facto de se tratar eventualmente de uma zona peri-urbana de um aglomerado urbano secundário e ainda zona de fronteira territorial e de convergência de eixos de circulação. Assim sendo, para além de se identificarem as variáveis de ordem natural que possam ter condicionado a implantação dos diversos tipos de povoamento (topografia, capacidade de uso dos solos, rede hidrográfica, geo/biodiversidade), procurava-se também avaliar a importância da proximidade de um hipotético vicus ou de vias de comunicação nesse processo de estruturação do povoamento.

Esta área foi prospectada ao longo de dois meses e em duas fases distintas mas sucessivas. A primeira, efectuada no âmbito do Seminário de Arqueologia Romana da licenciatura de História - variante de Arqueologia da FLUC, sob orientação do Prof. Doutor Jorge de Alarcão ${ }^{6}$, desenrolou-se durante os meses de Junho e Julho e incidiu sobre a área da freguesia de Capinha. A segunda, desenrolada já no âmbito do referido projecto de investigação, foi efectuada durante todo o mês de Agosto na área das freguesias de Salgueiro e Escarigo ${ }^{7}$.

Em ambas as fases, uma equipa de três ou quatro elementos percorreu toda esta área de uma forma organizada e sistemática, procurando sempre avançar em percursos paralelos, equidistantes e espaçados regularmente entre 20 a 50 metros, consoante a visibilidade e a acessibilidade do terreno ${ }^{8}$. Quando uma estação era identificada, para além de se obterem as respectivas coordenadas com recurso a um GPS de navegação com uma resolução na ordem dos 10 a 25 m, procedia-se ao registo de uma série de dados numa ficha de campo especialmente planeada para o efeito (Est. I). Posteriormente, os elementos recolhidos foram introduzidos numa base de dados concebida em FileMaker Pro, funcionando em estreita relação com um suporte cartográfico digital

5 Em vários locais, os limites da área prospectada coincidem com o início de zonas surribadas para a plantação de eucaliptos.

6 A quem expressamos a nossa gratidão pelo continuado incentivo.

7 Estes trabalhos contaram também com o apoio do Centro de Estudos Arqueológicos das Universidades de Coimbra e Porto e da Escola Profissional Agrícola Quinta da Lageosa - Belmonte. Agradecemos ainda a Paulo Gonçalves toda a colaboração dispensada.

${ }^{8}$ Em média foi necessário cerca de um dia de trabalho (c. 7 horas) para prospectar $1 \mathrm{~km}^{2}$, variando este valor em função essencialmente da intensidade da prospecção. 
com informação matricial e vectorial à escala 1/25.000 cedido pelo Instituto Geográfico do Exército 9 .

Os trabalhos de campo permitiram identificar 77 estações arqueológicas da época romana ${ }^{10}$, podendo ser consideradas inéditas 58 (75\%). A maioria das estações identificadas $(58 \%)$ corresponde a locais com áreas de concentração de materiais iguais ou inferiores a $600 \mathrm{~m}^{2}$.

Ainda que esta região em particular ofereça as condições mínimas necessárias para que esta metodologia de prospecção seja planeada e executada, não podemos, todavia, deixar de referir que a acção de diversos factores pós-deposicionais, naturais e antrópicos, acabou por condicionar em parte a execução do trabalho de campo e o processo de recolha e de interpretação dos vestígios de superfície. Por um lado, estes factores implicaram, provavelmente, a não localização de algumas estações em áreas densamente florestadas ou urbanizadas, dado aí ter sido manifestamente impossível pôr em prática o mesmo rigor e intensidade de prospecção, ou em áreas aplanadas constituídas por formações aluviais, onde existe a possibilidade de as estações se encontrarem encobertas por uma espessa camada de sedimentos. Por outro lado, a acção de outras variáveis, como seja o cultivo dos terrenos ou o manto vegetal que os cobre, ao condicionarem o grau de visibilidade dos dados de superfície, concorreram para as dificuldades que se colocaram ao nível da classificação tipológica dos sítios.

Não obstante estes condicionalismos, julgamos que os resultados deste processo de prospecção constituem uma imagem suficientemente representativa e fidedigna do tipo de povoamento romano e da forma como espacialmente se distribuía neste território em particular.

9 O sistema de informação geográfica que suporta este trabalho (e outros a efectuar no âmbito deste projecto) foi criado por António J. M. Silva (Post-Quem).

10 Foram identificadas e individualizadas como tal todas as concentrações de materiais arqueológicos à superfície ocupando uma área limitada e onde parecia existir uma ocupação ou arranjo intencional do espaço. Algumas das estações foram classificadas como romanas apenas pelo facto de se encontrarem tegulae à superfície, não obstante sabermos que este tipo de material de construção pode ter sido reutilizado em edificações posteriores. Outras, sem tegulae, foram também classificadas como romanas, com as devidas reservas, pelo facto de os materiais identificados, designadamente os fragmentos de dolia, serem semelhantes, em termos de forma e fabrico, àqueles localizados em sítios com comprovada ocupação romana e ainda por não aparecerem materiais inequivocamente de outras épocas (estes sítios poderão corresponder a casebres com cobertura de giesta ou de colmo). 


\section{Descrição e classificação das estações}

Apesar desta região, como anteriormente referimos, apresentar uma série de variáveis que condicionam, por vezes de forma decisiva, a representatividade ou a fiabilidade dos vestígios de superfície, parece ser possível desde já distinguir um vicus e classificar tipologicamente os outros sítios romanos em villae, quintas, casais e tuguria. Como critérios de classificação tipológica foram definidos, e utilizados sempre em articulação, a área de dispersão, a densidade/quantidade e qualidade dos materiais observados ou anteriormente referenciados e o tipo de implantação geo-morfológica.

Neste processo de classificação seguimos na generalidade os parâmetros propostos por Jorge de Alarcão para distinguir os diversos tipos de povoamento rural romano ${ }^{11}$. Pontualmente, porém, sentimos a necessidade de proceder a alguns ajustamentos ditados pelas características particulares que os núcleos rurais nesta região evidenciam ${ }^{12}$. Assim, se considerarmos que a casa que encabeçava um casal, para além da zona residencial, comportava também, eventualmente cobertos por outro(s) tecto(s), espaços reservados aos animais e à recolha dos produtos e instrumentos agrícolas, então teremos que considerar a possibilidade deste tipo de sítio poder corresponder sobretudo a locais com materiais à superfície dispersos por áreas entre os 1.000 e os $2.000 \mathrm{~m}^{213}$. No que concerne às quintas ou granjas, que nesta região parecem assumir o papel que noutras mais meridionais é desempenhado pelas villae ${ }^{14}$,

11 Jorge de Alarcão, "Paisagem rural romana e alto-medieval em Portugal", Conimbriga, vol. XXXVII, 1998, p. 89-119 (= Alarcão, 1998).

12 Estes ajustes nos parâmetros de classificação tipológica convergem no mesmo sentido daqueles definidos para a região do Alto Côa: Marcos Osório da Silva, O povoamento romano do Alto Côa, vol I, 2000, p. 88-89 (dissertação de Mestrado em Arqueologia, policopiada, apresentada à Faculdade de Letras de Coimbra) (= Osório, 2000).

13 Jorge de Alarcão, a este propósito, comunicou-nos que hoje considera sub-dimensionada a figura escolhida para representar um casal romano (1998, Est. V).

14 As prospecções que efectuámos até ao momento nos concelhos da Covilhã e do Fundão apontam no sentido das quintas constituírem a unidade fundiária por excelência desta região, tal como parece verificar-se na bacia média do Rio Côa e na bacia da Ribeira de Massueime: Manuel Sabino Perestrelo, O povoamento romano na bacia média do Rio Côa e na bacia da Ribeira de Massueime, vol. 1, 2000, p. 135 ss (dissertação de Mestrado em Arqueologia, policopiada, apresentada à Faculdade de Letras de Coimbra). 
a maior amplitude da sua área edificada poderá justificar, eventualmente, a fixação do limite superior das suas áreas de dispersão de materiais em torno dos $10.000 \mathrm{~m}^{215}$. Estas propostas, todavia, carecem de uma confirmação ou de uma revisão que, desejavelmente, deveria ser obtida com base no cruzamento dos dados proporcionados quer pela escavação integral de alguns sítios com estas características, quer por prospecções intensivas por quadriculagem levadas a cabo na área das próprias estações.

A problemática da classificação tipológica dos sítios romanos identificados em prospecção merece ser amplamente debatida ${ }^{16}$. Os trabalhos de prospecção realizados nos últimos anos e actualmente em curso, e as subsequentes análises sobre o povoamento, justificarão mesmo uma reflexão conjunta e alargada. A uniformização dos critérios de classificação tipológica das estações parece-nos, a par da adopção de metodologias de prospecção e de registo exaustivos similares, uma condição indispensável para que possam ser cotejados e articulados os resultados de distintos processos de investigação, permitindo deste modo visões de conjunto e tornando operativa a determinação fundamentada do padrão de povoamento à escala regional e supra-regional.

As estações arqueológicas cartografadas serão apresentadas segundo o seguinte esquema descritivo: número de identificação; designação e localização administrativa (topónimo - freguesia); coordenadas geográficas (UTM); descrição dos vestígios observados e sua área de dispersão; classificação cronológica e tipológica; referências bibliográficas, sendo algumas, quando se justifica, seguidas por uma relação sucinta dos materiais que referenciam e que nós não observámos.

15 Esta é a área aproximada, estimada empiricamente, de dispersão máxima de materiais do sítio de Terlamonte I (Teixoso, Covilhã), em fase de escavação, e que parece corresponder a uma quinta. Nesta caso em particular, porém, a área de dispersão de materiais poderá ultrapassar significativamente as dimensões da(s) área(s) edificada(s), resultando em parte do facto de este sítio, mas à semelhança de muitos outros com idêntica tipologia, se encontrar numa suave encosta periodicamente cultivada.

16 Uma das questões que merecerá ser equacionada prende-se com a eventual necessidade de se definirem parâmetros de classificação tipológica específicos em função das distintas áreas geográficas do país. 
Relação das estações arqueológicas identificadas:

1. Juais (Pêro Viseu): 635539/4450620; cerâmica de construção (tegulae) e cerâmica comum (dolia), dispersa por uma área aprox. de $400 \mathrm{~m}^{2}$; romano: tugurium; inédito.

2. Pontão (Capinha): 636208/4450802; cerâmica de construção (lateres) e cerâmica comum, dispersa por uma área aprox. de $100 \mathrm{~m}^{2}$; romano (?): tugurium; inédito.

3. Caverna III (Capinha): 636530/445280; cerâmica de construção (tegulae) e cerâmica comum (dolia), dispersa por uma área aprox. de $500 \mathrm{~m}^{2}$; romano: tugurium; inédito.

4. Caverna II (Capinha): 636700/4452380; cerâmica de construção (tegulae) e cerâmica comum, dispersa por uma área de $400 \mathrm{~m}^{2}$; romano: tugurium; inédito.

5. Currais I (Capinha): 636737/4451242; cerâmica de construção (tegulae), cerâmica comum e um fragmento de mó manual rotativa, dispersa por uma área aprox. de $900 \mathrm{~m}^{2}$ (?); romano: casal (?); inédito.

6. Currais II (Capinha): 636933/4450672; cerâmica de construção (tegulae) e cerâmica comum (dolia) dispersa por uma área aprox. de $900 \mathrm{~m}^{2}$; romano: casal; inédito.

7. Caverna I (Capinha): 636941/4452590; cerâmica de construção (tegulae), cerâmica comum (dolia), um peso de tear, uma moeda (AE de Constantino), um peso de chumbo, um fragmento de fivela e um fuzilhão de fíbula, dispersos por uma área aprox. de $5.000 \mathrm{~m}^{2}$; romano: quinta; Ramos, 1999, 36.

8. Tigelais V (Capinha): 637172/4450286; cerâmica de construção (tegulae e lateres) e cerâmica comum (dolia), abundante e dispersa por uma área de $1.200 \mathrm{~m}^{2}$; romano: casal; inédito.

9. Caverna IV (Capinha): 637172/4452894; cerâmica de construção (tegulae) e cerâmica comum (dolia) dispersa por uma área aprox. de $200 \mathrm{~m}^{2}$ (?); romano: tugurium; inédito.

10. Barroca I (Capinha): 637220/4451620; cerâmica de construção (tegulae) e cerâmica comum (dolia), escassa e dispersa por uma área aprox. de $400 \mathrm{~m}^{2}$; romano: tugurium; inédito.

11. Barroca IV (Capinha): 637300/4451480; cerâmica de construção (tegulae), cerâmica comum (dolia) e um peso de tear (e, nas proximidades, um denário - L FABI. L. F HISP. Q - cunhado em 82-81 a.C.), dispersa por uma área aprox. de $1.500 \mathrm{~m}^{2}$; romano: casal; inédito.

12. Tigelais IV (Capinha): 637291/4450406; cerâmica de construção (tegulae) e cerâmica comum (dolia), escassa e dispersa por uma área aprox. de $900 \mathrm{~m}^{2}$; romano: casal; inédito. 
13. Tigelais VI (Capinha): 637300/4450834; cerâmica de construção (lateres) e cerâmica comum, dispersa por uma área aprox. de $300 \mathrm{~m}^{2}$; romano (?): tugurium; inédito.

14. Tigelais II (Capinha): 637443/4450046; cerâmica de construção (tegulae) e cerâmica comum (dolia), dispersa por uma área aprox. de $600 \mathrm{~m}^{2}$; romano: tugurium; inédito.

15. Barroca II (Capinha): 637445/4451225; cerâmica de construção (tegulae) e cerâmica comum (dolia), dispersa por uma área aprox. de $400 \mathrm{~m}^{2}$; romano: tugurium; inédito.

16. Tigelais I (Capinha): 637564/4450570; cerâmica de construção (tegulae) e cerâmica comum (dolia), dispersa por uma área aprox. de $900 \mathrm{~m}^{2}$; romano: casal; Cristóvão, 1992, 73 (n. ${ }^{\circ}$ 108): um fragmento de tijolo para arco ou abóbada.

17. Barroca III (Capinha): 637595/4451273; cerâmica de construção (tegulae) e cerâmica comum (dolia), escassa e dispersa por uma área aprox. de $300 \mathrm{~m}^{2}$; romano: tugurium; inédito.

18. Tigelais VII (Capinha): 637616/4450707; cerâmica de construção (tegulae), escassa e dispersa por uma área aprox. de $400 \mathrm{~m}^{2}$; romano: tugurium; inédito.

19. Tigelais VIII (Capinha): 637621/4450789; cerâmica de construção (tegulae) e cerâmica comum (dolia), escassa e dispersa por uma área aprox. de $400 \mathrm{~m}^{2}$; romano: tugurium; inédito.

20. Rasas II (Capinha): 637704/4449614; cerâmica de construção (tegulae) e cerâmica comum (dolia), abundante e dispersa por uma área aprox. de $900 \mathrm{~m}^{2}$; romano: casal; inédito.

21. Tigelais IX (Capinha): 637750/4451108; cerâmica de construção (lateres) e cerâmica comum, escassa e dispersa por uma área aprox. de $400 \mathrm{~m}^{2}$; romano (?): tugurium; inédito.

22. Tigelais III (Capinha): 637769/4450808; cerâmica de construção (tegulae), cerâmica comum (dolia), duas moedas (AE - fruste - e AE2 - Teodósio -) terra sigillata hispânica, dispersa por uma área aprox. de $1.200 \mathrm{~m}^{2}$; romano: casal; Monteiro, 1978, 36; Cristóvão, 1992, 73 (n. ${ }^{\circ} 77$ ): silhares e uma mó.

23. Rasas I (Capinha): 637903/4449631; cerâmica de construção (tegulae), escassa e dispersa por uma área aprox. de $300 \mathrm{~m}^{2}$; romano: tugurium; inédito.

24. Bica (Capinha): 637949/4452448; cerâmica de construção (tegulae) e cerâmica comum (dolia), dispersa por uma área aprox. de 900 m²; romano: casal (?); Vasconcelos, 1917, 317: inscrição funerária, pedras aparelhadas e tijolos; Lambrino, 1956, n. ${ }^{\circ} 42$; Alarcão, 1988b, 4/ (p. 69); Cristóvão, 1992, 66 (n. $\left.{ }^{\circ} 100\right)$ : terra sigillata hispânica. 
25. Santana (Capinha): 638048/4451640; cerâmica de construção (lateres) e cerâmica comum, escassa e dispersa por uma área aprox. de $400 \mathrm{~m}^{2}$; romano (?): tugurium; inédito.

26. Capinha (Capinha): 638110/4451220; uma inscrição funerária, silhares (uma pedra almofadada), três pesos de lagar, cerâmica de construção (tegulae) e cerâmica comum (dolia), dispersa por uma área aprox. de 2 ha (?); romano: vicus (?); Vasconcelos, 1905, 321: inscrição votiva (= CIL II, 454)*; Proença, 1910a, 53: inscrição funerária (= CIL II, 453); Proença, 1910b, 4: moeda (aureus de Nero); Encarnação, 1975, 129-131; Vaz, 1977, 11-12 e 15-16: duas inscrições funerárias**; Monteiro, 1978, 69, 112 e 128: inscrição votiva, plinto de pequena coluna e moinho manual completo; Curado, 1987, n. ${ }^{\circ} 103$ (nota 2); Alarcão, 1988b, 4/370; Cristóvão, 1992, 67-72 (n. $\left.{ }^{\circ} 102\right)$ : dois capiteis toscanos (ou bases?) e uma moeda (denário?); Carvalho e Encarnação, 1994, 41-49; Ramos, 1999, 160: inscrição (romana?).

27. Cavalinho (Capinha): 638205/4452218; uma moeda (asse fruste), cerâmica de construção (tegulae), cerâmica comum, terra sigillata hispânica, dispersa por uma área aprox. de $900 \mathrm{~m}^{2}$; romano: casal (?); Ramos, 1999, 143.

28. Vinha Velha (Capinha): 638445/4450584; cerâmica de construção (tegulae), cerâmica comum (dolia) e escória, dispersa por uma área aprox. de $900 \mathrm{~m}^{2}$; romano: casal; Cristóvão, 1992, 73 (n. ${ }^{\circ} 109$ ).

29. Tapada das Argolas (Capinha): 638710/4452556; quatro moedas (três denários republicanos - cunhados em 133: L.MINVCI, 114-113: MN AEMILIO, LEP e 76-75 a.C.: EX SC, LENT, CVRFL - e um AE2 do final do século IV), uma fíbula "de cavalito" (Tipo D2) (Est. II), cerâmica comum (manual e a torno) e de construção (tegulae), muito dispersa por uma área difícil de determinar (surgem essencialmente nas imediações do cruzeiro); romano: indeterminado; Cristóvão, 1992, 65-66 (n. ${ }^{\circ}$ 98); Vilaça et alii, 2000, 204.

30. Tapada de S. Pedro (Capinha): 638918/4450378; cerâmica de construção (tegulae), cerâmica comum, dispersa por uma área aprox. de $900 \mathrm{~m}^{2}$, e reaproveitados nas paredes de uma casa encontram-se vinte e dois fustes de coluna e dois sarcófagos de pedra; romano: indeterminado; Monteiro, 1978, 30, 81 e 91: fustes de colunas, capitéis corín-

* Ainda que seja proveniente deste local, terá sido encontrada reutilizada na Tapada de S. Pedro: Cristóvão, 1992, 68.

** Estas placas, encontradas reutilizadas na ponte da Capinha, poderão ser atribuídas a este sítio: Cristóvão, 1992, 69. 
tios e inscrição funerária; Vaz, 1977, 19; Cristóvão, 1992, 68-69 e 73-74 (n. $\left.{ }^{\circ} 110\right)^{* * * ;}$ Ramos, 1999, 36, 146, 156 e 197-200.

31. Carvalhal (Capinha): 639247/4449833; cerâmica de construção (tegulae) e cerâmica comum (dolia), dispersa por uma área aprox. de $600 \mathrm{~m}^{2}$; romano: tugurium; inédito.

32. Porcaria II (Capinha): 639270/4451032; cerâmica de construção (tegulae) e cerâmica comum (dolia), escassa e dispersa por uma área aprox. de $400 \mathrm{~m}^{2}$; romano: tugurium; inédito.

33. Fundo do Cabeço da Vinha (Capinha): 639288/4450851; cerâmica de construção (tegulae), cerâmica comum (dolia), dispersa por uma área aprox. de $900 \mathrm{~m}^{2}$; romano: casal; inédito.

34. Porcaria I (Capinha): 639359/4450941; cerâmica de construção (tegulae) e cerâmica comum, escassa e dispersa por uma área aprox. de $200 \mathrm{~m}^{2}$; romano: tugurium; inédito.

35. Casal de José Seguro (Capinha): 639469/4450810; cerâmica de construção (tegulae), cerâmica comum, escassa e dispersa por uma área aprox. de $400 \mathrm{~m}^{2}$; romano: tugurium; inédito.

36. Santo António III (Capinha): 639530/4453819; cerâmica de construção (tegulae), cerâmica comum e terra sigillata hispânica, escassa e dispersa por uma área aprox. de $400 \mathrm{~m}^{2}$; romano: tugurium; inédito.

37. Casal de José Leal Feiteiro II (Capinha): 639738/4450920; cerâmica de construção (tegulae) e cerâmica comum (dolia), escassa e dispersa por uma área aprox. de $400 \mathrm{~m}^{2}$; romano: tugurium; inédito.

38. Santo António I (Capinha): 639866/4453653; cerâmica de construção (tegulae), cerâmica comum (dolia), terra sigillata hispânica, uma moeda ( $\mathrm{AE}$ - fruste) e uma mó manual rotativa, dispersa por uma área aprox. de $3.000 \mathrm{~m}^{2}$; romano: quinta (?); inédito.

39. Casal de José Leal Feiteiro I (Capinha): 639879/4450750; cerâmica de construção (tegulae) e cerâmica comum, abundante e dispersa por uma área aprox. de $600 \mathrm{~m}^{2}$; romano: casal (?); inédito.

40. Freixa (Capinha): 639931/4448881; cerâmica de construção (tegulae), cerâmica comum (dolia) e dormente de mó manual, dispersa por uma área aprox. de $3.000 \mathrm{~m}^{2}$; romano: quinta (?); inédito.

41. Santo António II (Capinha): 640089/4453581; cerâmica de construção (tegulae), escassa e dispersa por uma área aprox. de $200 \mathrm{~m}^{2}$; romano: tugurium; inédito.

*** Concordamos com J. Cristóvão quando considera que os elementos arquitectónicos e epigráficos aqui encontrados poderão ser provenientes do provável vicus situado na Capinha. 
42. Vale das Paredes (Capinha): 640314/4449421; cerâmica de construção (lateres) e cerâmica comum (dolia), dispersa por uma área aprox. de $600 \mathrm{~m}^{2}$; romano (?): tugurium; inédito.

43. Quinta da Malta II (Salgueiro): 641454/4453206; cerâmica de construção (tegulae) e cerâmica comum (dolia), abundante e dispersa por uma área aprox. de $3.000 \mathrm{~m}^{2}$; romano: quinta; inédito.

44. Quinta da Malta III (Salgueiro): 641545/4453473; cerâmica de construção (tegulae) e cerâmica comum, escassa e dispersa por uma área aprox. de $400 \mathrm{~m}^{2}$; romano: tugurium; inédito.

45. Quinta da Malta IV (Salgueiro): 641654/4452902; cerâmica de construção (tegulae) e cerâmica comum, escassa e dispersa por uma área aprox. de $200 \mathrm{~m}^{2}$; romano: tugurium; inédito.

46. Quinta da Malta V (Salgueiro): 641653/4453230; cerâmica de construção (tegulae) e cerâmica comum, escassa e dispersa por uma área aprox. de $400 \mathrm{~m}^{2}$; romano: tugurium; inédito.

47. Quinta da Malta VI (Salgueiro): 641761/4452652; cerâmica de construção (tegulae) e cerâmica comum, escassa e dispersa por uma área aprox. $400 \mathrm{~m}^{2}$; romano: tugurium; inédito.

48. Quinta da Malta I (Salgueiro): 641819/4452817; cerâmica de construção (tegulae) e cerâmica comum (dolia), dispersa por uma área aprox. de $600 \mathrm{~m}^{2}$; romano: tugurium; Cristóvão, 1992, 61 (n. ${ }^{\circ}$ 96).

49. Quinta da Malta VIII (Salgueiro): 642028/4452988; cerâmica de construção (tegulae) e cerâmica comum, dispersa por uma área aprox. de $600 \mathrm{~m}^{2}$; romano: tugurium; inédito.

50. Prado Vasco II (Salgueiro): 642145/4451105; cerâmica de construção (tegulae), cerâmica comum (dolia) e silhares, abundante e dispersa por uma área aprox. de $900 \mathrm{~m}^{2}$; romano: tugurium (?); inédito.

51. Quinta da Malta VII (Salgueiro): 642393/4452619; cerâmica de construção (tegulae) e cerâmica comum, dispersa por uma área aprox. de $600 \mathrm{~m}^{2}$; romano: tugurium; inédito.

52. Prado Vasco I (Salgueiro): 642352/4452062; abundante cerâmica de construção (tegulae), cerâmica comum (dolia), terra sigillata hispânica, uma moeda, duas base de coluna, três fustes de coluna e silhares, dispersos por uma área aprox. de $10.000 \mathrm{~m}^{2}$; romano: villa; Cristóvão, 1992, 66-67 (n. $\left.{ }^{\circ} 101\right)$.

53. Prado Vasco III (Salgueiro): 642553/4452045; cerâmica de construção (tegulae), cerâmica comum e terra sigillata hispânica, dispersa por uma área aprox. de $600 \mathrm{~m}^{2}$; romano: tugurium; inédito.

54. Quinta do João Silvestre I (Salgueiro): 643795/4452386; cerâmica de construção (later) e cerâmica comum, escassa e dispersa por uma área aprox. de $400 \mathrm{~m}^{2}$; romano (?): tugurium; inédito. 
55. Lameirões I (Salgueiro): 643605/4454223; cerâmica de construção (tegulae) e cerâmica comum (dolia), abundante e dispersa por uma área aprox. de $1.200 \mathrm{~m}^{2}$; romano: casal; inédito.

56. Lameirões II (Salgueiro): 643828/4454718; cerâmica de construção (tegulae) e cerâmica comum, dispersa por uma área aprox. de $400 \mathrm{~m}^{2}$; romano: tugurium; inédito.

57. Lameira Longa I (Salgueiro): 643856/4454628; cerâmica de construção (tegulae) e cerâmica comum, escassa e dispersa por uma área aprox. de $600 \mathrm{~m}^{2}$; romano: tugurium; inédito.

58. Lameira Longa II (Salgueiro): 644021/4454956; cerâmica de construção (lateres) e cerâmica comum (dolia), escassa e dispersa por uma área aprox. de $600 \mathrm{~m}^{2}$; romano (?): tugurium; inédito.

59. Quinta do João Silvestre II (Salgueiro): 644054/4452306; cerâmica de construção (tegulae) e cerâmica comum (dolia), dispersa por uma área aprox. de $900 \mathrm{~m}^{2}$; romano: casal (?); inédito.

60. Quinta do João Silvestre III (Salgueiro): 644069/4452095; cerâmica de construção (lateres) e cerâmica comum, escassa e dispersa por uma área aprox. de $400 \mathrm{~m}^{2}$; romano (?): tugurium; inédito.

61. Moita do Pinhal (Salgueiro): 644268;4452637; cerâmica de construção (tegulae) e cerâmica comum (dolia), dispersa por uma área aprox. de $1.200 \mathrm{~m}^{2}$; romano: casal; inédito.

62. Lameira Longa III (Salgueiro): 644362/4454522; cerâmica de construção (tegulae) e cerâmica comum (dolia), dispersa por uma área aprox. de $900 \mathrm{~m}^{2}$; romano: casal (?); inédito.

63. Coito de Baixo II (Salgueiro): 644472/4453041; cerâmica de construção (tegulae) e cerâmica comum (dolia), dispersa por uma área aprox. de 900 m²; romano: casal; Cristóvão, 1992, 59-60 (n. ${ }^{\circ} 93$ e 94): nas proximidades terá sido encontrado um tesouro monetário.

64. Coito de Baixo I (Salgueiro): 644682/4453025; cerâmica de construção (tegulae) e cerâmica comum (dolia), escassa e dispersa por uma área aprox. de $600 \mathrm{~m}^{2}$; romano: tugurium; Cristóvão, 1992, 59 (n. $\left.{ }^{\circ} 91\right)$.

65. Coito de Cima I (Salgueiro): 645350/4453600; cerâmica de construção (tegulae) e cerâmica comum (dolia), dispersa por uma área aprox. $900 \mathrm{~m}^{2}$; romano: casal (?); Cristóvão, 1992, 58 (n. ${ }^{\circ} 88$ ): terra sigillata hispânica e clara D e dormente de moinho manual.

66. Quinta do Vale Carneiro I (Escarigo): 645418/4455890; cerâmica de construção (tegulae), cerâmica comum e terra sigillata hispânica, escassa e dispersa por uma área aprox. de $400 \mathrm{~m}^{2}$; romano: tugurium (?); inédito.

67. Coito de Cima II (Salgueiro): 645475/4453475; duas pedras facetadas, cerâmica de construção (tegulae) e cerâmica comum, escassa 
e dispersa por uma área aprox. de $200 \mathrm{~m}^{2}$; romano: tugurium; Cristóvão, 1992, 58 (n. ${ }^{\circ}$ 89): terra sigillata hispânica, uma moeda (sestércio) e um dormente de moinho manual.

68. Fragana (Escarigo): 645532/4456303; cerâmica de construção (tegulae) e cerâmica comum (dolia), escassa e dispersa por uma área aprox. de $900 \mathrm{~m}^{2}$; romano: casal (?); inédito.

69. Quinta do Vale Carneiro II (Escarigo): 645919/4455957; cerâmica de construção (tegulae) e cerâmica comum (dolia), escassa e dispersa por uma área aprox. de $400 \mathrm{~m}^{2}$; romano: tugurium; inédito.

70. Casal I (Escarigo): 646275/4456270; cerâmica de construção (tegulae) e cerâmica comum (dolia), dispersa por uma área aprox. de $1.500 \mathrm{~m}^{2}$; romano: casal; inédito.

71. Quinta da Caldeirinha (Salgueiro): 646300/4453475; cerâmica de construção (tegulae), dispersa por uma área aprox. de $100 \mathrm{~m}^{2}$; romano: tugurium; Cristóvão, 1992, 58 e 59 (n. $\left.{ }^{\circ} 90\right)$.

72. Casal II (Escarigo): 646388/4456048; cerâmica de construção (tegulae) e cerâmica comum (dolia), dispersa por uma área aprox. de $1.200 \mathrm{~m}^{2}$; romano: casal; inédito.

73. Lameira da Tenda (Escarigo): 646772/4455992; cerâmica de construção (tegulae) e cerâmica comum (dolia), dispersa por uma área aprox. de $1.500 \mathrm{~m}^{2}$; romano: casal; inédito.

74. Vale do Casal I (Escarigo): 646917/4454370; cerâmica de construção (tegulae) e cerâmica comum (dolia), dispersa por uma área aprox. de $2.500 \mathrm{~m}^{2}$; romano: casal (?); Cristóvão, 1992, 53 (n. ${ }^{\circ}$ 75): terra sigillata hispânica e dormente de moinho manual.

75. Tapada do Seixo (Escarigo): 647100/4454641; cerâmica de construção (tegulae) e cerâmica comum, escassa e dispersa por uma área aprox. de $600 \mathrm{~m}^{2}$; romano: tugurium; Cristóvão, 1992, 50 (n. ${ }^{\circ} 68$ ).

76. Lavajola (Escarigo): 647107/4454487; cerâmica de construção (lateres) e cerâmica comum, dispersa por uma área aprox. de $400 \mathrm{~m}^{2}$; romano (?): tugurium; Cristóvão, 1992, 51 (n. $\left.{ }^{\circ} 71\right)$ (?): tegulae.

77. Vale do Casal II (Escarigo): 647318/4453951; cerâmica de construção (tegulae) e cerâmica comum (dolia), escassa e dispersa por uma área aprox. de $600 \mathrm{~m}^{2}$; romano: tugurium; inédito.

\section{Uma primeira abordagem interpretativa}

Uma análise preliminar dos resultados da prospecção intensiva efectuada permite verificar que a malha do povoamento ao longo do curso inferior e médio da Ribeira da Meimoa é formada por uma série 
de pequenos núcleos rurais interpretáveis como espaços habitacionais, sedes de pequenas e/ou médias propriedades, ou como simples anexos destes. Com efeito, os dados agora recolhidos parecem sugerir que as villae - se entendidas como sedes de grandes explorações agro-pecuárias de proprietários cuja riqueza e integração nos valores da cultura clássica se manifestava nomeadamente na presença dos urbana ornamenta nas suas residências - não seria a forma de povoamento mais comum e característico nesta paisagem rural. Nesta área, apenas classificamos como villa a estação $52^{17}$. As restantes, a partir dos vestígios superficiais que encontramos, poderão ser interpretadas como quintas ou sedes de médias propriedades (n. ${ }^{\circ}$, 38, 40 e 43) ou então como simples casais habitados por famílias de parcos recursos ou ainda como pequenos casebres que constituiriam alguns deles uma base de apoio às actividades agro-pecuárias dos núcleos habitacionais.

A distinção entre estas pequenas unidades de exploração agrária unifamiliares coloca, na maior parte dos casos, inúmeras dificuldades pelo facto de estarmos unicamente a lidar com vestígios superficiais que nem sempre reflectem, de forma fidedigna, a natureza do sítio que os originou. A ambiguidade dos vestígios torna particularmente problemática a distinção entre os dois tipos de sítios que constituem a grande maioria dos locais identificados: os casais e os tuguria ${ }^{18}$. Essa distinção, no entanto, poderá em certos casos ser inclusivamente artificial, uma vez que muitos dos sítios que designamos por tuguria seriam também modestas residências unifamiliares, sendo apenas arrecadações ou anexos aqueles que se localizavam no aro de influência de um núcleo mais importante.

Na grande maioria destes sítios não foi possível recolher materiais que permitissem propor uma cronologia de ocupação precisa para cada um. Sendo assim, todos eles são colocados sobre uma mesma malha de povoamento, assentando a análise interpretativa no pressuposto de que, pelo menos a dada altura, a generalidade dos sítios foi contemporânea. Este facto, nesta fase dificilmente contornável, concorre indubitavelmente para uma cristalização da imagem proporcionada pela prospec-

17 Refira-se, porém, que na envolvência imediata da área prospectada, designadamente na Quinta da Caneca, Alagoas e no Casal do José Francisco do Anascer, se encontram estações que poderão ser classificadas como villae: cf. Cristóvão, 1992, 33-36, 40 e 45.

18 Estes, em conjunto, representam $89 \%$ do total de sítios identificados, situando-se ambos habitualmente no topo de pequenas colinas e apresentando áreas de dispersão de materiais muito reduzidas. 
ção, quando, à partida, o que seria desejável era considerar o território e a paisagem rural como um sistema dinâmico sujeito à acção de variáveis que evoluem de modo diferenciado com o decurso do tempo.

As características dos vestígios identificados na área da povoação de Capinha e a notória concentração de núcleos de povoamento rural nesse local parece reforçar uma hipótese anteriormente sugerida: a possibilidade da existência aqui de um aglomerado urbano secundário ( $v i$ $(u s)^{19}$, posicionado numa área de fronteira territorial ${ }^{20}$ e de convergência de eixos principais de circulação.

Com efeito, o tipo de sítios identificados e a forma como estes se distribuem nesta zona parece sugerir a presença de um centro populacional que polariza em seu torno uma série de pequenos núcleos (Est. III e IV). Esse centro, palco propiciador de diversos serviços - comerciais, artesanais, administrativos e religiosos - poderia situar-se sob a actual aldeia de Capinha, ocupando designadamente um esporão, estrategicamente posicionado sobre o vale onde confluem a Ribeira da Meimoa e o Ribeiro das Poldras, no qual se encontram à superfície por uma vasta área, ainda que de forma escassa e dispersa, materiais romanos. A estes indicadores deverá juntar-se todo um conjunto de achados que têm sido referenciados para esta povoação, nomeadamente de natureza arquitectónica e epigráfica (funerária e votiva) ${ }^{21}$, e o próprio posi-

19 Esta hipótese é habitualmente admitida por alguns autores (Alarcão, 1988 a, 78 e 101; Alarcão, 1988 b, 4/370; Alarcão, 1998, 148) ainda que afastem a possibilidade deste corresponder ao vicus Talabara mencionado numa inscrição rupestre funerária encontrada em Capinha (CIL II 453 = ILER 5511). Todavia, o argumento geralmente invocado para não validar essa correspondência não nos parece inquestionável, uma vez que, por exemplo, em Idanha existem epígrafes funerárias onde se encontra claramente expressa a origo egitaniense (cf. CIL II 61 e 62 e ILER 5322).

20 O limite dos territoria das civitates dos Ocelenses Lancienses e dos Igaeditani poderia correr por algumas das cumeadas que bordejam a sul o vale da ribeira da Meimoa (Alarcão, 2001, 297 e 299). A hipótese da existência da civitas dos Ocelenses na época de Augusto (Alarcão e Imperial, 1996, 39-44) não merece, porém, a concordância de todos: Amílcar Guerra, Nomes pré-romanos de povos e lugares do Ocidente peninsular, Lisboa, 1998 (dissertação de doutoramento, policopiada, apresentada à Faculdade de Letras de Lisboa).

21 A estes materiais já referenciados (cf. estação n. ${ }^{\circ}$ 26) junta-se o achado recente, efectuado aquando da demolição de uma casa na Travessa da Rua Direita, em Capinha, de mais uma inscrição que daremos a conhecer num dos próximos números do "Ficheiro Epigráfico" e cuja onomástica reforça ainda mais o indigenismo destas populações. 
cionamento geográfico deste sítio, provavelmente junto à bifurcação da via que saindo da civitas Igaeditanorum se dirigia para norte, seguindo quer para o Vale do Zêzere, por Pêro Viseu, quer para a região do Alto Côa, por Salgueiro ${ }^{22}$. A ser assim, este local possuiria inclusivamente os requisitos necessários para que aí, nas imediações de um importante povoado fortificado pré-romano ${ }^{23}$, se tenha estabelecido uma mutatio ou uma mansio, cujo dinamismo, aliás, poderia mesmo ter dado origem a um pequeno vicus.

Em torno deste povoado aberto de génese romana, adentro do seu território de 30 minutos (Est. IV), sobretudo na área de influência ou de captação directa que se estende a sul, de maior aptidão agrícola, onde era possível um policultivo mais intenso (horti), gravitava uma série de pequenos aedificia. Alguns, encontrar-se-iam na dependência das famílias que residiam no povoado, constituindo simples arrecadações. Outros, sobretudo aqueles que se situam para além do território de 15 minutos, poderiam albergar permanentemente pequenos núcleos familiares ${ }^{24}$.

Na cintura que envolve o território imediato de exploração do alegado vicus, encontram-se os sítios que classificámos como quintas. À excepção do sítio 43, que revela características muito particulares, os restantes (n. ${ }^{\circ}$ 7, 38 e 40 ) têm em comum o facto de se situarem em regiões mais acidentadas e menos férteis em termos agrícolas ${ }^{25}$, o que

22 Nesta freguesia, no lugar do Coito de Cima, mas possivelmente já deslocado do seu local original de deposição, foi encontrado um miliário: Vaz, 1977, 25-26 e Curado, 1982, 87.

23 O povoado da Vila Velha (ou Tapada das Argolas), em função de alguns achados avulsos e significativos aqui efectuados (cf. estação arqueológica n. ${ }^{\circ} 29$ ), parece ter sobrevivido, pelo menos numa fase inicial, à ocupação romana. Entre esses achados, para além dos denários, destaca-se um exemplar das fíbulas "de cavalito" do tipo D2, particularmente características do mundo céltico peninsular entre os finais do séc. III a. C. e as guerras sertorianas, e possivelmente utilizadas pelas élites equestres e guerreiras indígenas como símbolo distintivo: M. Almagro-Gorbea e M. Torres Ortiz, Las fíbulas de jinete e de caballito: aproximación a la elites ecuestres y su expansión en la Hispania céltica, Institución "Fernando El Católico", Zaragoza, 1999.

24 Situação semelhante parece também poder identificar-se em torno da capital da civitas Igaeditanorum, onde prospecções igualmente intensivas permitiram identificar uma série de pequenos núcleos rurais: Alarcão, 1998, 103-104.

25 Também no Alto Côa, as quintas situam-se, ao contrário das villae, a altitudes mais elevadas, demonstrando uma menor exigência na qualidade dos solos: Osório, 2000,88 . 
parece revelar uma especial apetência pelo pastoreio e criação de gado ou pelas culturas de sequeiro, e terem associados pelo menos dois pequenos sítios, certamente com funções específicas e posicionados em pontos nevrálgicos da propriedade. Os círculos que traçamos em redor de duas quintas - efectuados de forma a englobar os respectivos estabelecimentos dependentes - representam propriedades da ordem dos 43 hectares, no caso da estação 38, e da ordem dos 74 hectares, no caso da estação 7 (Est. IV) ${ }^{26}$.

Localizada nas proximidades de um complexo de pequenos sítios e de uma quinta, na margem oposta da ribeira, a cerca de $4 \mathrm{~km}$ do vicus, encontra-se o único sítio que nesta área classificamos como villa. Os vestígios, abundantes e significativos, estendem-se por uma área que poderá ultrapassar ligeiramente 1 hectare e concentram-se em duas manchas contíguas mas descontínuas, podendo estas eventualmente corresponder à pars urbana $\left(n .^{\circ} 52\right)$ e à pars rustica $\left(n .^{\circ} 50\right)$ da villa. Próximo, a cerca de $200 \mathrm{~m}$, uma outra pequena concentração de materiais (n. ${ }^{\circ}$ 53) parece testemunhar a existência de um aedificium anexo. $\mathrm{O}$ particular posicionamento desta unidade fundiária, numa plataforma sobranceira à ribeira e a uma planura de terrenos alagadiços e no sopé de uma área montanhosa, deixa antever a possibilidade de exploração duma ampla gama de recursos naturais.

A malha de povoamento identificada ao longo do restante vale marcado pelo curso da Ribeira da Meimoa apresenta outras características, alternando áreas vazias de povoamento com áreas de estações concentradas em agrupamentos, posicionando-se estas em ambas as margens da ribeira, geralmente no topo de pequenas colinas com declives suaves ou moderados e nas proximidades de uma via que correria ao longo da margem direita da ribeira dirigindo-se para nordeste (Est. III).

Com efeito, a presença de pequenos núcleos rurais avulsos mas congregados em áreas restritas do território e distanciados entre si escassas centenas de metros (entre 100 a 500 m), avistando-se entre si,

26 No segundo caso, uma actividade eminentemente pastoril (e uma menor produtividade agrícola dessas terras) poderá justificar a existência de propriedades com áreas superiores aos 50 hectares propostos por Jorge de Alarcão para os fundi das granjas: Alarcão, 1998, 97. 
configura um tipo de povoamento que poderíamos designar por disperso agrupado ${ }^{27}$. Se alguns destes agrupamentos poderão constituir um povoamento de tipo orbiculado, resultante do facto de existirem uma série de pequenos núcleos que se encontram na estreita dependência ou sob domínio directo de uma villa $\left(\mathrm{n}^{\circ}{ }^{\circ}\right.$ 52) ou, eventualmente, de uma quinta (n. ${ }^{\circ} 7,38,40$ e 43 ), outros há que, pelo facto de os seus núcleos reflectirem características igualitárias marcadamente rústicas, não se evidenciando uma estação que se assuma claramente como sede de um fundus com uma considerável amplitude, poderão ser interpretados como pequenos aglomerados populacionais campesinos, com espaços residenciais ou áreas construídas descontínuas e autónomas, pertencentes a unidades familiares independentes que exploram pequenas propriedades convizinhas que andariam em torno dos 10-20 hectare $^{28}$. A confirmar-se esta proposta, poderíamos estar em presença de um modelo de povoamento em parte constituído por lugarejos descerrados, não arruados, formados por agrupamentos esparsos de 4 a 8 pequenas casas rurais que se abriam para os caminhos vicinais e para as parcelas de terreno em redor que cultivavam ${ }^{29}$. Estes complexos de sítios poderiam mesmo ter-se desenvolvido a partir da instalação inicial de uma família nuclear que gradualmente se multiplicou e fragmentou ${ }^{30}$,

27 Sobre os distintos padrões de distribuição das estações, cf.: Ian Hodder y Clive Orton, Spatial analysis in archaeology, Cambridge University Press, Cambridge, 1976, p. 30 ss (= Hodder y Orton, 1976).

28 A área cultivada, porém, sem recurso a mão-de-obra servil ou exterior à família, poderia não ultrapassar os 2 ou 3 hectares.

29 Este tipo de povoamento rural parece estabelecer notórias afinidades com aquele que Leite de Vasconcelos identificou ainda no Entre-Douro-e-Minho e na Beira, onde se verificavam pequenos conjuntos de casas, cada uma regularmente com o seu terreno, e afastadas umas das outras, tomando por vezes o nome de "casal" no sentido de "lugarejo", podendo um conjunto de "lugares" formar uma povoação de casas disseminadas: J. Leite de Vasconcelos, Etnografia Portuguesa, vol. II, Imprensa Nacional - Casa da Moeda, 1995, p. 274-277 e 302 ss; também Orlando Ribeiro faz referência, para as regiões do Minho, Ribatejo e Algarve, a lugares de poucos moradores, com as casas frouxamente agrupadas, e campos, prados e arvoredos, insinuados entre elas: Orlando Ribeiro, Hermann Lautensach, Suzanne Daveau, Geografia de Portugal, III. O Povo Português, Lisboa, 1989, p. 861-869.

30 Este processo de "expansão contagiosa" poderá afirmar-se como factor determinante deste tipo de distribuição de sítios habitacionais concentrados em agrupamentos em áreas onde os factores geo-ambientais pareçam não assumir particular relevância: Hodder y Orton, 1976, 85 ss. 
segundo um modelo que se encontra atestado em algumas paisagens rurais da Britania romana, podendo neste caso, através da manutenção de laços familiares e sociais cooperativos, explorar um fundo comum e indiviso ${ }^{31}$.

Estas comunidades campesinas, porém, poderiam também explorar terras arrendadas, pertencentes às elites indígenas locais que residiam no vicus e que controlavam indirectamente a produção dos seus fundi a partir desse centro urbano ${ }^{32}$, fomentando a produção de excedentes e gerando novas formas de dependência social através da instituição dum sistema de tributação.

$\mathrm{O}$ alargamento da área prospectada afigura-se, no entanto, como algo de fundamental para a validação da hipótese formulada, uma vez que estes agrupamentos de pequenos núcleos rurais poderão encontrar-se directamente vinculados a quintas ou villae situadas imediatamente para além dos limites da área estudada ${ }^{33}$.

Seja como for, a necessidade de explorar directamente uma gama de recursos naturais diversificados parece explicar o seu posicionamento em áreas de solos com boa capacidade de uso agrícola, situados numa zona de transição entre os lameiros nas margens da ribeira e as superfícies montanhosas, quase sempre no intervalo altimétrico dos 450$-500 \mathrm{~m}$, e na proximidade da zona de contacto entre xistos e granitos (c. $1 \mathrm{~km}$ para NO) onde são frequentes nascentes de água e ocorrências de minérios (estanho e tungsténio). Neste sentido, estes núcleos de povoamento rural poderiam enquadrar-se numa economia de tipo agro-

31 Para além dos "farm compounds" (quintas cercadas albergando famílias extensas), aí são também frequentes os grupos de casas rurais dispersas, não se distanciando umas das outras mais do que $500 \mathrm{~m}$, pertencendo presumivelmente a diversas famílias mas que descendem duma mesma família nuclear original, podendo por isso explorar em comum uma mesma área de pastos e terra arável: Richard Hingley, Rural Settlement in Roman Britain, Seaby, London, 1989, p. 95 ss.

32 À semelhança do que se verifica em Trás-os-Montes Oriental, a epigrafia funerária nesta área surge no vicus ou nas suas imediações, podendo relacionar-se com o grupo local de grandes proprietários que aí residia: F. Sande Lemos, Povoamento Romano de Trás-os-Montes Oriental, vol. I-b, Universidade do Minho, Braga, 1993, p. 390 e ss e 452 (dissertação de Doutoramento em Arqueologia, policopiada).

33 A inscrição votiva e o mascarão de sítula, que terão sido encontrados, respectivamente, em Salgueiro e Escarigo (Alarcão, 1998b, 4/371 e 4/373), poderão sugerir a presença de núcleos de maior envergadura, situando-se, eventualmente, no local das actuais povoações. 
pastoril, marcadamente complementada pela mineração ${ }^{34}$, cujos excedentes seriam canalizados para os mercados dos aglomerados urbanos secundários que se encontravam nas proximidades ${ }^{35}$.

Se um dos méritos da prospecção intensiva reside no facto de permitir identificar uma percentagem seguramente muito significativa dos núcleos de povoamento antigo, incluindo aqueles que surgem representados por pequenas áreas de dispersão de materiais à superfície, outro dos méritos consiste na possibilidade de se constatar a existência de áreas sem estações arqueológicas.

Se a ausência de povoamento antigo em certas áreas poderá explicar-se por razões de ordem geomorfológica e ambiental, quer por serem zonas agrestes com declives acentuados e solos esqueléticos (como será o caso da Nave Redonda), quer por serem zonas de terrenos alagadiços, pesados, formados por depósitos aluviais (como se verifica ao longo das margens da Ribeira da Meimoa), noutras áreas a inexistência de núcleos rurais não poderá ser explicada de igual forma, uma vez que se trata de zonas que em termos geo-ambientais são em tudo idênticas àquelas onde surgem os agrupamentos de estações. Assim sendo, estas ausências poderão antes relacionar-se com a forma de estruturação do povoamento e de exploração do território, podendo estes vazios, contíguos às parcelas cultivadas, constituir as áreas de actividade limitada dos diversos núcleos populacionais, nas quais se encontravam os pastos e as matas ${ }^{36}$, provavelmente de usufruto comuni-

34 Também na área da Sierra de Francia (Ciudad Rodrigo), a paisagem, na época romana, parece resultar de uma síntese entre actividades agrárias e mineiras: M. Ruiz del Árbol e F.-J. Sánchez-Palencia, "Organización y explotación del territorio en el Noreste de Lusitania: Las Cavenes de el Cabaco", Actas do III. ${ }^{\circ}$ Congresso de Arqueologia Peninsular, vol. VI, ADECAP, Porto, 2000, p. 116-129.

35 Os sítios na extremidade oriental da zona prospectada poderiam encontrar-se já na área de influência de um outro provável vicus, que se chamaria Venia, situado na Meimoa (sobre este vicus: Alarcão, 1988b, 4/375).

36 Os resultados das análises polínicas do "Charco da Candieira" (Serra da Estrela) ou da "Zona Arqueológica de Las Cavenes" (Ciudad Rodrigo) parecem sugerir para esta época, em traços gerais, a ocorrência de um processo de desflorestação (que se traduz essencialmente no decréscimo do pinheiro) acompanhado pelo início do cultivo do castanheiro e da nogueira e pela expansão dos bosques de carvalhais, de medronhais e de urzes: W. O. van der Knaap e J. F. N. van Leeuwen, "Holocene vegetation succession and degradation as responses to climatic change and human activity in the Serra da Estrela, Portugal", Review of Paleobotany and Palynology, 89, 1995, p. 201; 
tário (compascua ou communalia) $)^{37}$, e, eventualmente, alguns locais relacionados com a actividade extractiva artesanal de minério.

Em suma, perante o exposto, parece-nos evidente que a configuração matricial do povoamento pré-romano nesta região terá sido pulverizada logo nos inícios do séc. I d. C., provavelmente a partir do momento em que se terão constituído as civitates. Com efeito, o abandono do povoado da Tapada das Argolas terá sido acompanhado pela multiplicação gradual de núcleos rurais de fundação romana que se instalam nas terras baixas do vale, em áreas até então não povoadas, e que gravitam em torno de um pequeno núcleo urbano (ou proto-urbano) que centraliza e desempenha algumas funções de índole administrativa, comercial e religiosa. Este novo modelo de ocupação e organização do espaço, criado e marcado por comunidades rurais para as quais a epigrafia sugere uma fácies claramente indígena, inscreve-se num quadro administrativo e fiscal provincial imposto por Roma que exige um novo sistema de exploração do território, que se traduz no alargamento das áreas cultivadas e na intensificação da produção, e que pressupõe uma ruptura das formações étnicas e sócio-económicas anteriores.

Por último, o facto de o conjunto de sítios identificados se distribuir de forma não aleatória mas tendencialmente agrupada a espaços regulares vem no fundo sublinhar a necessidade de entendermos a paisagem como uma construção social resultante da interacção de distintas variáveis e no seio das quais a localização e a perceptibilidade dos recursos naturais têm decerto um peso considerável ${ }^{38}$.

Não procurámos aqui de forma alguma esgotar todas as possibilidades de análise que os dados resultantes de prospecções intensivas proporcionam, nem tão pouco explorar as potencialidades da inserção deste tipo de dados num sistema de informação geográfica.

F. Javier Sánchez-Palencia e María Ruiz del Árbol, "Estruturas agrarias y explotación minera en Lusitania nororiental: la Zona Arqueológica de Las Cavenes (El Cabaco, Salamanca), Sociedade y cultura en Lusitania romana, Mérida, 2000, p. 353-354.

37 Sobre a categoria jurídica das terras: Paz Lopez Paz, La Ciudad Roman Ideal (1. El territorio), Santiago de Compostela, 1994, p. 207 e 211.

38 Sublinhe-se, todavia, que se o comportamento espacial poderá ser fundamentalmente racional em termos económicos, este não é necessariamente óptimo e nunca é exclusivamente económico: Karl W. Butzer, Arqueología - Una ecología del hombre: método e teoría para un enfoque contextual, Ed. Bellaterra, Barcelona, 1989, p. 247. 
Uma análise mais ampla e profunda, tendo como objectivo geral o estabelecimento de um padrão de ocupação e organização da paisagem e do território romano para esta região, só será efectuada após o alargamento da área prospectada intensivamente.

BIBLIOGRAFIA (referente à área em estudo):

Alarcão, Jorge de (1988a) - O Domínio Romano em Portugal, Publ. Europa-América. Alarcão, Jorge de (1988b) - Roman Portugal, vol. II, fasc. 1, Gazetteer, Warminster. AlARCÃO, Jorge de (1998) - "On the civitates mentioned in the inscription on the bridge at Alcântara", Journal of Iberian Archaeology, Porto, 0, p. 143-157. AlARCÃo, Jorge de (2001) - "Novas perspectivas sobre os Lusitanos (e outros mundos)", Revista Portuguesa de Arqueologia, vol. 4, número 2, Lisboa, p. 293-349. Alarcão, Jorge de; IMPERIAL, Flávio (1996) - "Sobre a localização dos Lancienses e Tapori”, Miscellanea em homenagem ao Professor Bairrão Oleiro, Lisboa, p. 39-44.

Albertos Firmat, Maria Lourdes; Bento, Mário Pires (1977) - "Testemunhos da ocupação romana na região de Meimoa (Beira Baixa)", Congreso Nacional de Arqueologia, Zaragoza, p. 1197-1208.

Cardoso, J. Ribeiro (1940) - "Subsídios para a História Regional da Beira Baixa", Castelo Branco, vol. 1, Junta Provincial da Beira Baixa, Castelo Branco, p. 7-29. CARvalho, Rogério; EnCARnaÇão, José d' (1994) - "Inscrição rupestre romana procedente de Capinha”, Trebaruna, 3, CEEB, Castelo Branco, p. 41-49.

Cortez, F. Russell (1952) - "Os Tapori de Plínio. Subsídios para a sua localização", Zephyrus, 3 (2), Salamanca, p. 175-178.

CRistóvão, José L. (1992) - O povoamento romano da bacia do curso médio da Ribeira da Meimoa, Instituto de Arqueologia da Faculdade de Letras da Universidade de Coimbra (seminário de Arqueologia: trabalho académico policopiado).

Curado, Fernando P. (1982) - “A viação romana no concelho de Penamacor. Contribuição para o estudo da via de Mérida a Braga”, Actas e Memórias do $1 .^{\circ}$ Colóquio de Arqueologia e História do Concelho de Penamacor, Penamacor. Curado, Fernando P. (1987) - "Fragmento de Ara de Nisa", Ficheiro Epigráfico, 23, Coimbra, n. ${ }^{\circ} 103$.

EnCARnAÇão, José d' (1975) - Divindades indígenas sob o domínio romano em Portugal, Lisboa, Imprensa Nacional Casa da Moeda.

LAmBrino, Scarlat (1956) - "Les inscriptions latines inédites du Musée Leite de Vasconcelos”, O Arqueólogo Português, 2. érie, vol. III, p. 5-73.

LEITÃo, Manuel (1979) - "Notas para um inventário arqueológico do distrito de Castelo Branco - Capinha”, Reconquista, ano 35, n. ${ }^{\circ}$ 1767, Castelo Branco.

MonteIro, José Alves (1942) - "Ara e cipo miliário inéditos", Novidades, 30.VIII e 6.IX.1942. 
Monteiro, José Alves (1978) - Pequena história de um museu: fundo e catálogo. Carta arqueológica do concelho do Fundão, Lisboa.

ProençA, Francisco Tavares (1910a) - "Inscrições inéditas", O Archeólogo Português, vol. XV, p. 39-54.

ProençA, Francisco Tavares (1910b) - Archeologia do Districto de Castello Branco, Leiria.

Ramos, S. Caldeira (1999) - Memórias da Capinha (Uma Aldeia no Concelho do Fundão).

SAA, Mário (1964) - As grandes vias da Lusitânia. O Itinerário de Antonino Pio, vol. 5, Lisboa.

Salvado, António (1976) - "Elementos para um inventário artístico do distrito de Castelo Branco", Estudos de Castelo Branco, nova série, vol. 1, Castelo Branco, p. 3-40.

VASCONCELOS, J. Leite de (1905 e 1913) - Religiões da Lusitânia, vol. 2 e 3, Imprensa Nacional de Lisboa.

VAsConcelos, J. Leite de (1917) - "Pela Beira", O Archeólogo Português, vol. XXII, p. 293-344.

VAsConcelos, J. Leite de (1924) - "Figuras de bronze antigas do Museu Ethnologico Português", O Archeólogo Português, vol. XXVI, p. 29-36.

VAZ, João I. (1977) - "Inscrições romanas do Museu do Fundão", Conimbriga, vol. XVI, p. 5-31.

Vilaça, Raquel; André T. SAntos; Eduardo Porfírio; João N. Marques; Miguel Correia; Nuno Canas (2000) - “ O povoamento do I milénio a.C. na área do concelho do Fundão”, Estudos Pré-Históricos, vol. VIII, CEPBA, p. 187-219. 


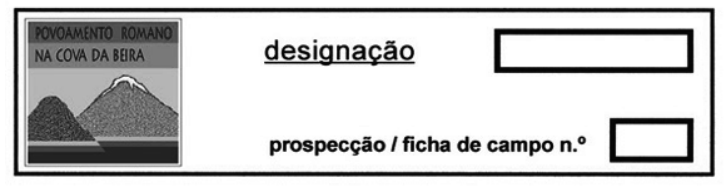

data

assinatura

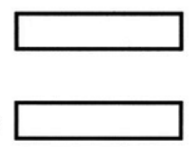

localização administrativa

topónimo(s)

freguesia

concelho
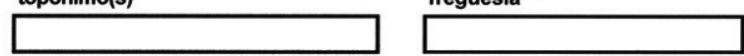

localização geográfica (UTM)

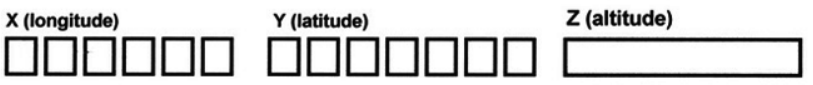

CMP $1 / 25.000$

enquadramento geomorfológico e ambiental

descrição e classificação dos vestígios

área de dispersão

quantificação

visibilidade

condicionantes
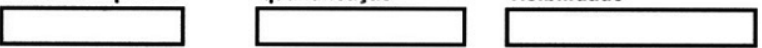

descrição materiais

classificação cronológica

registo fotográfico

rolo

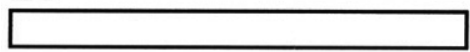

classificação tipológica

foto 

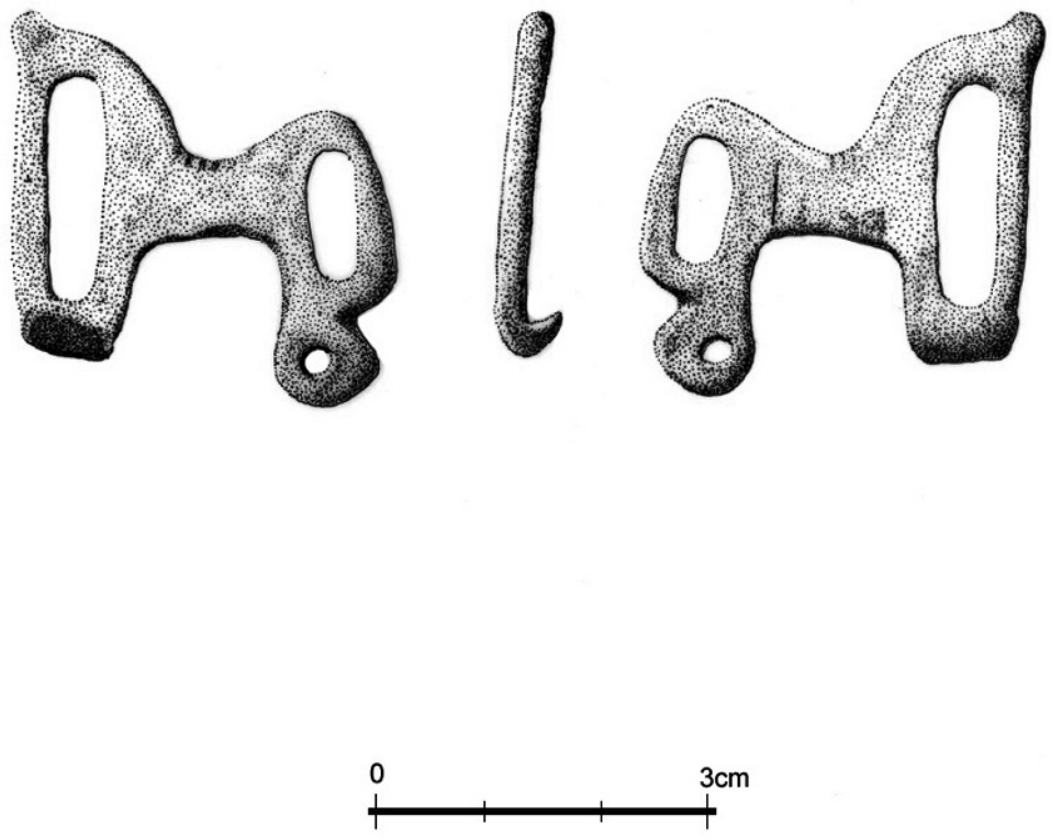

Des.: Zé Augusto 


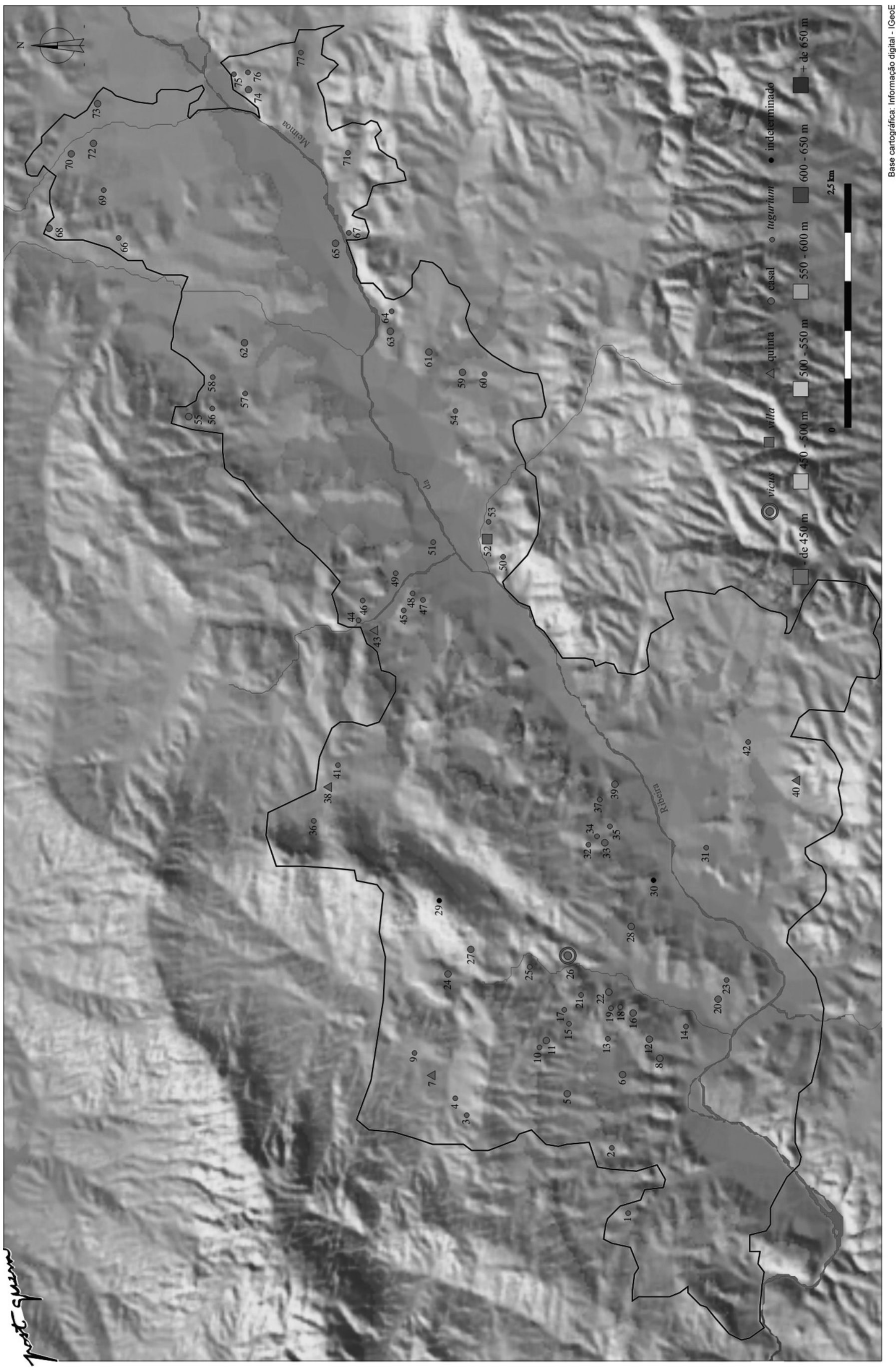




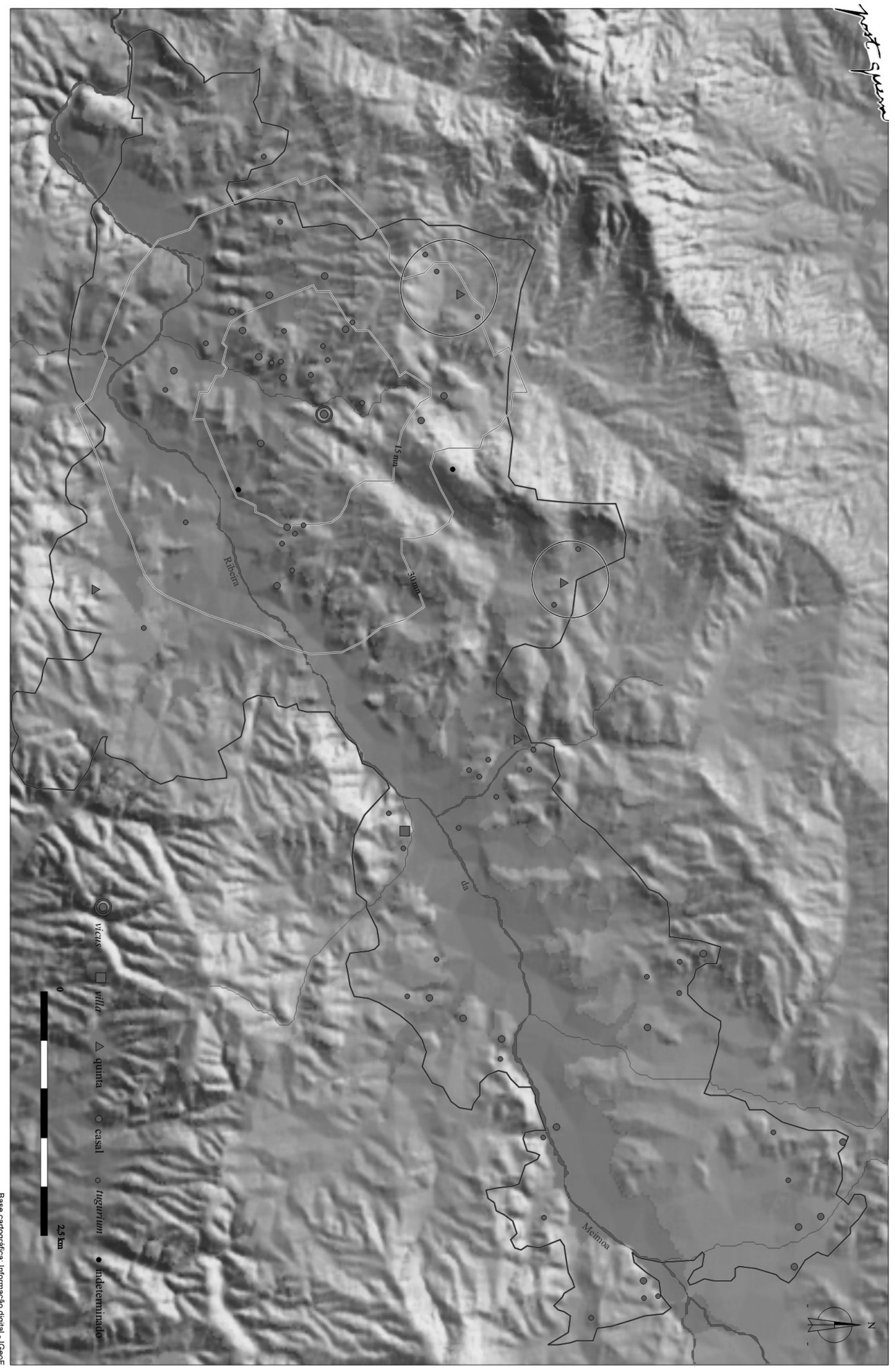

